\title{
Paeoniflorin Enhances Endometrial Receptivity through Leukemia Inhibitory Factor
}

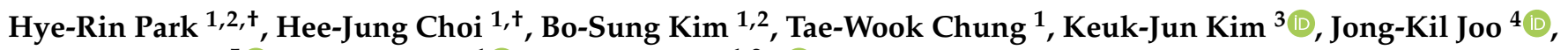 \\ Dongryeol Ryu ${ }^{5} \mathbb{C}$, Sung-Jin Bae ${ }^{1}(\mathbb{D})$ and Ki-Tae $\mathrm{Ha}^{1,2, * \mathbb{C}}$
}

1 Korean Medical Research Center for Healthy Aging, Pusan National University, Yangsan, Gyeongsangnam-do 50612, Korea; rin8998@pusan.ac.kr (H.-R.P.); hjchoi@pusan.ac.kr (H.-J.C.); kkc0704@pusan.ac.kr (B.-S.K.); twchung@pusan.ac.kr (T.-W.C.); Dr.NowOrNever@pusan.ac.kr (S.-J.B.)

2 Department of Korean Medical Science, School of Korean Medicine, Pusan National University, Yangsan, Gyeongsangnam-do 50612, Korea

3 Department of Clinical Pathology, Daekyeung University, Gyeongsan, Gyeongsanabuk-do 38547, Korea; biomed@tk.ac.kr

4 Department of Obstetrics and Gynecology, School of Medicine, Pusan National University Hospital, Busan 49241, Korea; jkjoo@pusan.ac.kr

5 Department of Molecular Cell Biology, Sungkyunkwan University School of Medicine, Suwon 16419, Korea; freefall@skku.edu

* Correspondence: hagis@pusan.ac.kr; Tel.: +82-51-510-8464; Fax: +82-51-510-8420

+ These authors contributed equally in this study.

check for

updates

Citation: Park, H.-R.; Choi, H.-J.; Kim, B.-S.; Chung, T.-W.; Kim, K.-J.; Joo, J.-K.; Ryu, D.; Bae, S.-J.; Ha, K.-T. Paeoniflorin Enhances Endometrial Receptivity through Leukemia Inhibitory Factor. Biomolecules 2021, 11, 439. https://doi.org/10.3390/ biom 11030439

Academic Editor:

Joanna Kolniak-Ostek

Received: 4 February 2021

Accepted: 15 March 2021

Published: 16 March 2021

Publisher's Note: MDPI stays neutral with regard to jurisdictional claims in published maps and institutional affiliations.

Copyright: (c) 2021 by the authors. Licensee MDPI, Basel, Switzerland. This article is an open access article distributed under the terms and conditions of the Creative Commons Attribution (CC BY) license (https:// creativecommons.org/licenses/by/ $4.0 /)$.

\begin{abstract}
Despite advances in assisted reproductive technology, treatment for deficient endometrial receptivity is a major clinical unmet need. In our previous study, the water extract of Paeonia lactiflora Pall. enhanced endometrial receptivity in vitro and in vivo via induction of leukemia inhibitory factor (LIF), an interleukin (IL)-6 family cytokine. In the present study, we found that paeoniflorin, a monoterpene glycoside, is the major active compound of P. lactiflora. Paeoniflorin significantly improved the embryo implantation rate in a murine model of mifepristone (RU486)-induced implantation failure. In addition, paeoniflorin increased the adhesion of human trophectoderm-derived JAr cells to endometrial Ishikawa cells through the expression of LIF in vitro. Moreover, using the National Center for Biotechnology Information (NCBI) Gene Expression Omnibus (GEO) database of the human endometrium, we confirmed that LIF signaling is a key regulator for improving human endometrial receptivity. Therefore, these results suggest that paeoniflorin might be a potent drug candidate for the treatment of endometrial implantation failure by enhancing endometrial receptivity.
\end{abstract}

Keywords: paeoniflorin; endometrial receptivity; embryo implantation; leukemia inhibitory factor

\section{Introduction}

A receptive endometrium is a crucial factor for successful pregnancy [1]. Despite advances in assisted reproductive technology (ART), the implantation success rates of transferred embryo have not sufficiently improved [2]. To evaluate and improve endometrial receptivity, vigorous studies, including on endometrial receptivity array and intentional endometrial injury, have been conducted [3,4]. However, there are very limited clinical options for improving endometrial receptivity [5]. Thus, more precise, comprehensive, and novel approaches for enhancing endometrial receptivity are needed.

Endometrial receptivity is regulated by diverse factors such as hormones, cytokines, and growth factors $[1,3]$. Among these factors, leukemia inhibitory factor (LIF), a cytokine belonging to the interleukin (IL)-6 family, has been regarded as a key player regulating uterine receptivity $[6,7]$. LIF exhibits a multifaceted action by activating many pathways, including epithelial-mesenchymal transition, angiogenesis, stromal cell decidualization, cell growth, and integrin signaling [6]. Previous studies have demonstrated that LIF enhances endometrial receptivity by activating Arg-Gly-Asp (RGD)-binding integrins 
such as integrin $\alpha \mathrm{V}, \beta 3$, and $\beta 5$ [8-10]. Thus, in this study, we aimed to identify novel agents that improve endometrial receptivity by inducing LIF expression [11-14].

In our previous study, the root of Paeonia lactiflora Pall. enhanced endometrial via induction of LIF [12]. P. lactiflora is widely used for the treatment of gynaecological problems, pain, cramp, and giddiness in traditional Chinese medicine [15]. It has also been studied for its effects on diverse diseases including tumors, hepatitis, diabetes, arthritis, and colitis $[16,17]$. According to previous reports, paeoniflorin, a major ingredient of P. lactiflora, has anti-inflammatory effects on various inflammatory disorders including inflammatory bowel disease, rheumatoid arthritis, asthma, and psoriasis [18]. In addition, paeoniflorin has been reported to suppress epithelial-mesenchymal transition in mouse pulmonary fibrosis [19] and attenuate insulin resistance and hepatic steatosis [20]. Although the effect of $P$. lactiflora on endometrial receptivity was previously demonstrated by the authors $[12,21]$, no study has reported the effect of paeoniflorin on embryo implantation.

In this study, we demonstrated that paeoniflorin increased embryo implantation in both in vitro and in vivo models. In addition, we found that the expression of LIF played an important role in paeoniflorin-stimulated adhesion of trophoblasts to the endometrium. Therefore, our findings present evidence showing that paeoniflorin could be a potent agent for improving endometrial receptivity.

\section{Materials and Methods}

\subsection{Materials}

Paeoniflorin ( $\geq 98 \%$ purity using high-performance liquid chromatography (HPLC)), gallic acid ( $\geq 99 \%$ purity, HPLC), ( \pm )-catechin ( $\geq 96 \%$ purity, HPLC), (+)-catechin hydrate ( $\geq 98 \%$ purity, HPLC), methyl gallate ( $\geq 90 \%$ purity, HPLC), paeonol ( $\geq 98 \%$ purity, HPLC), mifepristone (RU486; RU, progesterone receptor antagonist), 3-(4,5-dimethylthiazol-2-yl)2,5-diphenyltetrazolium bromide (MTT), and anti- $\beta$-actin antibody were purchased from Sigma-Aldrich (St. Louis, MO, USA). Antibodies against LIF were supplied by Santa Cruz Biotechnology Inc. (Santa Cruz, CA, USA).

\subsection{Traditional Chinese Medicine Systems Pharmacology (TCMSP) Analysis}

The Traditional Chinese Medicine Systems Pharmacology TCMSP (https:/ tcmspw. $\mathrm{com} /$ (accessed on 15 March 2021)) database is useful for evaluating the absorption, distribution, metabolism, and excretion (ADME) processes of compounds. To screen P. lactiflora for potential candidate components, we selected compounds with an oral bioavailability $(\mathrm{OB}) \geq 30 \%$ and drug likeness (DL) $\geq 0.18$.

\subsection{Animals}

Male and female C57BL / 6 mice (7-8 weeks old, weighing 20-22 g) inbred in a specific pathogen-free facility were purchased from Orient Bio, Co. (Seongnam, Korea). They were housed separately and had free access to water and a standard diet on a $12 \mathrm{~h} \mathrm{light/dark}$ cycle. All experimental procedures were reviewed and approved by the Animal Research Ethics Committee of Pusan University of Korea (no. PNU-2017-1606).

\subsection{Animal Models and Treatment}

The experiment using the embryo implantation failure model was performed as previously described [12]. Briefly, 40 female mice were randomly divided into four groups: control, $R U$, paeoniflorin $+R U$, and paeoniflorin groups. Female mice in the paeoniflorin $+R U$ and paeoniflorin groups were orally administered paeoniflorin $\left(8 \mathrm{mg} \cdot \mathrm{kg}^{-1} \cdot \mathrm{day}^{-1}\right)$ using oral gavage needles. Seven days after paeoniflorin treatment, all the female mice were caged with males (ratio, 1:1) at 6:00 p.m., and day 1 of pregnancy was defined by the presence of vaginal plugs the following morning. Female mice in the RU and paeoniflorin $+\mathrm{RU}$ groups were injected subcutaneously with $0.08 \mathrm{mg} / 0.1 \mathrm{~mL} R \mathrm{R}$ solution on day 4-7 of pregnancy at 9:00 a.m.. Seven days after RU treatment, all mice were euthanized, and both 
uterine horns were excised to determine the number of implantation sites. The embryos implanted on each uterine site were counted.

\subsection{Cell Culture}

Human endometrial Ishikawa cells provided by Dr. Jacques Simard (CHUL Research Center, Quebec City, QC, Canada) and trophoblastic JAr cells purchased from the Korean Cell Line Bank (Seoul, Korea) were incubated with 10\% heat-inactivated fetal bovine serum (FBS; Thermo Fisher Scientific, Waltham, MA, USA) in Dulbecco's modified Eagle's medium (DMEM; Welgene, Daegu, Korea) and Roswell Park Memorial Institute (RPMI) 1640 (Welgene), respectively. The cultures were maintained at $37{ }^{\circ} \mathrm{C}$ in a humidified incubator containing $5 \%$ carbon dioxide $\left(\mathrm{CO}_{2}\right)$.

\subsection{Cell Viability Assay}

The MTT assay was performed to measure the in vitro cytotoxicity of paeoniflorin on Ishikawa cells [22]. The cells were cultured in 24-well plates, treated with the indicated concentrations of paeoniflorin for $24 \mathrm{~h}$, and washed three times with phosphate-buffered saline (PBS); then, MTT solution $(0.5 \mathrm{mg} / \mathrm{mL})$ was added to each well. After a $4 \mathrm{~h}$ incubation, the cells were dissolved in a solution of dimethyl sulfoxide (DMSO)/ethanol (EtOH, 1:1) and the absorbance was measured at $540 \mathrm{~nm}$ using a microplate reader (SpectraMax M2; Molecular Devices, San Jose, CA, USA). The proportion of live cells was determined and expressed as a percentage.

\subsection{Western Blot Analysis}

Western blot assays were performed as described previously [23]. Ishikawa cells were collected by scraping in $1 \% \mathrm{NP}-40$ lysis buffer and incubated for $1 \mathrm{~h}$ at $4{ }^{\circ} \mathrm{C}$. The cell lysates were clarified by centrifuge at $15,000 \mathrm{rpm}$ for $30 \mathrm{~min}$, followed by protein quantification with Bradford assay (Bio-Rad, \# 5000006). The extracted proteins (20 $\mu \mathrm{g}$ ) were separated using sodium dodecyl sulfate polyacrylamide gel electrophoresis (SDS-PAGE) and transferred onto nitrocellulose membranes (Amersham Protran, 10600003). After preincubation with blocking solution (5\% skim-milk/Tris-buffered saline plus Tween (TBST)) for $1 \mathrm{~h}$, the membranes were incubated with specific primary antibodies, which were diluted to 1:1000 in TBS-T, at $4{ }^{\circ} \mathrm{C}$ overnight. Then, the membranes were incubated with horseradish peroxidase-conjugated secondary antibodies (1:1000 in TBS-T), and the signals were visualized using an enhanced chemiluminescence (ECL) system (GE Healthcare, Chicago, IL, USA).

\subsection{Reverse Transcription Polymerase Chain Reaction (RT-PCR)}

Total RNA from each sample was isolated using RiboEx ${ }^{\mathrm{TM}}$ (GeneAll, Seoul, Korea) and then reverse-transcribed using oligo-dT primers with M-MLV reverse transcriptase (Enzynomics, Daejeon, Korea). The complementary DNA (cDNA) was amplified by PCR using AccuPower ${ }^{\circledR}$ PCR PreMix (Bioneer Co., Daejeon, Korea). The primers used were as follows: LIF forward, 5'-GGCCCGGACACCCATAGACG-3' and LIF reverse, $5^{\prime}-$ CCACGCGCCATCCAGGTAAA-3'; $\beta$-actin forward, $5^{\prime}$-CAAGAGATGGCCACGGCTGCT$3^{\prime}$ and $\beta$-actin reverse, $5^{\prime}$-TCCTTCTGCATCCTGTCGGCA- $3^{\prime}$.

\subsection{Cell Adhesion Assay}

Cell adhesion assays were performed as described previously with minor modification [24]. Ishikawa, pLKO.1, and siLIF-transfected cells were cultured in six-well plates for $24 \mathrm{~h}$ and then treated with paeoniflorin for $48 \mathrm{~h}$. The JAr cells were labeled with 5-chloromethylfluoresceindiacetate (CMFDA) fluorescence dye (CellTracker Green; Life Technologies) for $15 \mathrm{~min}$ at $37^{\circ} \mathrm{C}$. The labeled JAr cells were then washed three times with PBS and gently added to Ishikawa cell monolayers. After gentle shaking at $40 \mathrm{rpm}$ for 30 min at $37^{\circ} \mathrm{C}$, the cells were washed three times to remove non-adherent JAr cells. The number of attached JAr cells was visualized using a fluorescent microscope (Axio Imager 
M1, Zeiss, Oberkochen, Germany) and calculated using the ImageJ software (National Institutes of Health (NIH), Bethesda, MD, USA).

\subsection{Knockdown of LIF Expression}

To temporally reduce the expression of LIF, we purchased two different small interfering RNAs (siRNAs, Bioneer Co.) and tested the efficiency of knockdown of human LIF expression. The siRNA sequences used in this study were as follows: siLIF\#1 sense, $5^{\prime}$-CAGAUGUUCCUGCCUUAGA- $3^{\prime}$ and siLIF\# 1 antisense, $5^{\prime}$-UCUAAGGCA GGAACAUCUG- $3^{\prime}$; siLIF\#2 sense, $5^{\prime}$-CCUCCGACAAGAUGAUGGU- $3^{\prime}$ and siLIF\#2 antisense, $5^{\prime}$-ACCAUCAUCUUGUCGGAGG-3' ${ }^{\prime}$. Two siRNAs $(0.8 \mathrm{nM})$ were transfected into Ishikawa cells using Lipofectamine 2000 (Invitrogen, Carlsbad, CA, USA). After $6 \mathrm{~h}$, the medium was changed to complete growth medium. A non-targeting siRNA (SN-1001-CFG; Bioneer Co.), with low homology to human genomic DNA was used as a negative control. The efficiency of the siRNAs was evaluated using RT-PCR.

\subsection{Bioinformatic Analysis}

Publicly available microarray data were used for transcript expression analysis [25-27]. Transcriptomic data for the human endometrium obtained from patients with recurrent implantation failure (RIF) and fertile women (accession number GSE71835, GSE92324, and GSE26787) and data for normal tissue from various phases of the menstrual cycle (accession number GSE4888) were analyzed using the Hallmark and gene set enrichment analysis (GSEA) [28].

\subsection{Protein-Protein Physical Interaction Network Analysis}

The networks were created using GeneMANIA (https:/ / genemania.org (accessed on 15 March 2021)), and the physical interaction between two proteins was represented using an edge [29].

\subsection{Statistical Analysis}

The intensity of the bands obtained from RT-PCR were quantified with ImageJ software. The results were statistically analyzed using the Student's $t$-test and a one-way analysis of variance (ANOVA) with Tukey's post hoc test using the GraphPad Prism (GraphPad Software, San Diego, CA, USA). Values are expressed as means \pm standard error of the mean (SEM). The minimum significance level was set at a $p$-value $=0.05$. All experiments, except for the animal studies, were independently performed at least three times.

\section{Results}

\subsection{Effects of Compounds from P. lactiflora on LIF Expression and In Silico ADME Properties}

First, we tested six major compounds from P. lactiflora [12], and their molecular structures are presented in Figure 1A. Ishikawa cells were treated with these six compounds. To evaluate their potential enhancement of endometrial receptivity, we compared the expression levels of LIF. Our results showed that methyl gallate, paeoniflorin, and paeonol increased LIF protein expression levels (Figure 1B). Second, we investigated the pharmacokinetic parameters of $P$. lactiflora on the basis of the network pharmacology using TCMSP.

Twenty-nine compounds satisfied both the $\mathrm{OB} \geq 30 \%$ and the DL $\geq 0.18$ criteria, and, among the previously reported six components of P. lactiflora, only (+)-catechin and paeoniflorin and its nine derivative compounds satisfied these conditions (Table 1 and Figure S1, Supplementary Materials). In particular, gallic acid, methyl gallate, and paeonol did not satisfy the OB and DL screening criteria (Table S1, Supplementary Materials). In addition, $(-)$-catechin and (+)-catechin hydrate were not included in the list obtained from the TCMSP analysis. According to the data from TCMSP-based in silico ADME and Western blot analysis, paeoniflorin might be an active component of $P$. lactiflora. 


\section{A)}

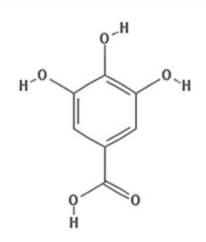

Gallic acid

(3,4,5-trihydroxybenzoic acid)

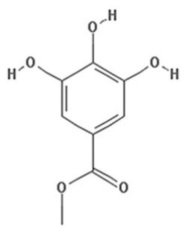

Methyl gallate

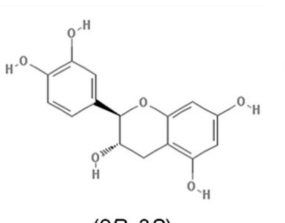

$(2 R, 3 S)$<smiles>Cc1cc(N)cc2c1C[C@H](N)[C@H](c1ccc(O)c(O)c1)O2</smiles>

$(2 S, 3 R)$<smiles>O=C(O)C1Cc2c(O)cc(O)cc2OC1c1ccc(O)c(O)c1</smiles>

${ }^{\circ}{ }^{\circ}$

(+)-Catechin hydrate

(士)-Catechin

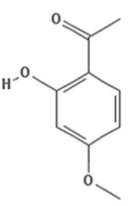

Paeonol

B)

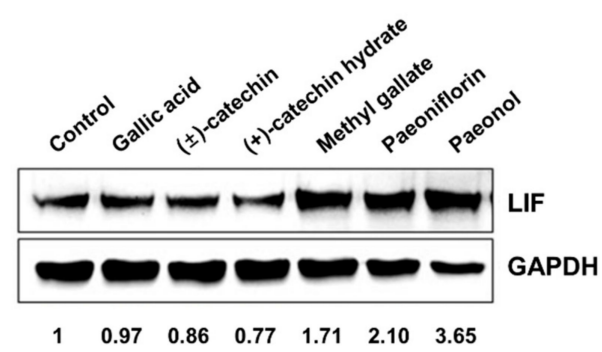

Figure 1. Paeoniflorin is the most active component of Paeonia lactiflora in improving endometrial receptivity. (A) Structures of major components of P. lactiflora. (B) Ishikawa cells were treated with indicated six compounds for $24 \mathrm{~h}$ and then harvested for Western blot analysis. The expression level of leukemia inhibitory factor (LIF) was used for screening.

Table 1. Twenty-nine components of Paeonia lactiflora satisfied oral bioavailability (OB) $\geq 30 \%$ and drug likeness (DL) $\geq 0.18$ obtained from Traditional Chinese Medicine Systems Pharmacology (TCMSP).

\begin{tabular}{|c|c|c|c|c|c|c|c|}
\hline Molecule Name & MW & OB $(\%)$ & DL & $\mathbf{A} \log P$ & Hdon & Hacc & Caco-2 \\
\hline Paeoniflorgenone * & 318.35 & 87.59 & 0.37 & 0.79 & 1 & 6 & -0.09 \\
\hline Paeoniflorin_qt* & 318.35 & 68.18 & 0.4 & 0.46 & 2 & 6 & -0.34 \\
\hline Paeoniflorigenone ${ }^{*}$ & 318.35 & 65.33 & 0.37 & 0.79 & 1 & 6 & -0.13 \\
\hline $1-O-\beta$-D-Glucopyranosylpaeonisuffrone_qt & 332.38 & 65.08 & 0.35 & 0.51 & 1 & 6 & -0.05 \\
\hline Evofolin B & 318.35 & 64.74 & 0.22 & 2.07 & 3 & 6 & 0 \\
\hline 9-Ethyl-neo-paeoniaflorin A_qt * & 334.4 & 64.42 & 0.3 & 1.48 & 1 & 6 & -0.01 \\
\hline (2R,3R)-4-Methoxyl-distylin & 318.3 & 59.98 & 0.3 & 1.89 & 4 & 7 & 0.17 \\
\hline 4-Ethyl-paeoniflorin_qt * & 332.38 & 56.87 & 0.44 & 1.02 & 1 & 6 & -0.17 \\
\hline 4-O-Methyl-paeoniflorin_qt * & 332.38 & 56.7 & 0.43 & 0.87 & 1 & 6 & 0.4 \\
\hline$(+)$-Catechin & 290.29 & 54.83 & 0.24 & 1.92 & 5 & 6 & -0.03 \\
\hline Paeoniflorin * & 480.51 & 53.87 & 0.79 & -1.28 & 5 & 11 & -1.47 \\
\hline Lactiflorin & 462.49 & 49.12 & 0.8 & -0.57 & 3 & 10 & -1.13 \\
\hline Albiflorin_qt & 318.35 & 48.7 & 0.33 & 0.42 & 2 & 6 & -0.38 \\
\hline Stigmasterol & 412.77 & 43.83 & 0.76 & 7.64 & 1 & 1 & 1.44 \\
\hline Ellagic acid & 302.2 & 43.06 & 0.43 & 1.48 & 4 & 8 & -0.44 \\
\hline Spinasterol & 412.77 & 42.98 & 0.76 & 7.64 & 1 & 1 & 1.44 \\
\hline Baicalin & 446.39 & 40.12 & 0.75 & 0.64 & 6 & 11 & -0.85 \\
\hline Campest-5-en-3 $\beta$-ol & 400.76 & 37.58 & 0.71 & 7.63 & 1 & 1 & 1.32 \\
\hline Stigmast-7-en-3-ol & 414.79 & 37.42 & 0.75 & 8.08 & 1 & 1 & 1.32 \\
\hline$\beta$-Sitosterol & 414.79 & 36.91 & 0.75 & 8.08 & 1 & 1 & 1.32 \\
\hline Sitosterol & 414.79 & 36.91 & 0.75 & 8.08 & 1 & 1 & 1.32 \\
\hline 1-O- $\beta$-D-Glucopyranosyl-8-O-benzoylpaeonisuffrone_qt * & 302.35 & 36.01 & 0.3 & 0.44 & 1 & 5 & -0.03 \\
\hline
\end{tabular}


Table 1. Cont.

\begin{tabular}{|c|c|c|c|c|c|c|c|}
\hline Molecule Name & MW & OB (\%) & DL & $A \log P$ & Hdon & Hacc & Caco-2 \\
\hline Baicalein & 270.25 & 33.52 & 0.21 & 2.33 & 3 & 5 & 0.63 \\
\hline Ethyl oleate (NF) & 310.58 & 32.4 & 0.19 & 7.44 & 0 & 2 & 1.4 \\
\hline 8-Debenzoylpaeonidanin & 390.43 & 31.74 & 0.45 & -3.28 & 5 & 10 & -1.56 \\
\hline Benzoyl paeoniflorin * & 584.62 & 31.14 & 0.54 & 0.76 & 4 & 12 & -1.35 \\
\hline Isobenzoylpaeoniflorin * & 584.62 & 31.14 & 0.54 & 0.76 & 4 & 12 & -0.85 \\
\hline Albiflorin & 480.51 & 30.25 & 0.77 & -1.33 & 5 & 11 & -1.52 \\
\hline$(1 S, 2 S, 4 R)$-trans-2-Hydroxy-1,8-cineole- $\beta$-D-glucopyranoside & 332.44 & 30.25 & 0.27 & -0.57 & 4 & 7 & -0.77 \\
\hline
\end{tabular}

Note: * paeoniflorin and its derivatives. MW, molecular weight; OB, oral bioavailability; DL, drug likeness; AlogP, octanol-water partition coefficient $\log$ P; Hdon, hydrogen donor; Hacc, hydrogen bond acceptor; Caco-2, Caco-2 permeability.

\subsection{Effect of Paeoniflorin on Endometrial Receptivity of Implantation-Depleted Mouse Model}

The previously reported RU-induced implantation depletion model $[12,30]$ was used to evaluate the in vivo effect of paeoniflorin on embryo implantation (Figure 2A). The results showed that the number of implanted embryos in the paeoniflorin + RU group $(8.17 \pm 2.99)$ was significantly higher than that in the RU group $(0.17 \pm 0.41)$. Although the number of embryos in the paeoniflorin $(8.50 \pm 0.84)$ and paeoniflorin + RU groups were slightly higher than those in the control group $(7.50 \pm 1.38)$, there were no statistically significant differences (Figure 2B,C). The histological observations showed that there were no fetal regression sites in the paeoniflorin-treated groups. In addition, the dose of paeoniflorin used in the animal study did not induce any toxicities on liver or kidney functions according to the analysis of the aspartate transaminase (AST), alanine transaminase (ALT), and BUN (blood urea ni-trogen) levels (Figure S2, Supplementary Materials). These findings indicated that paeoniflorin prevented the implantation defect induced by RU treatment.

A)

Paeoniflorin $\left(8 \mathrm{mg} \cdot \mathrm{kg}^{-1} \cdot\right.$ day $\left.^{-1}\right)$

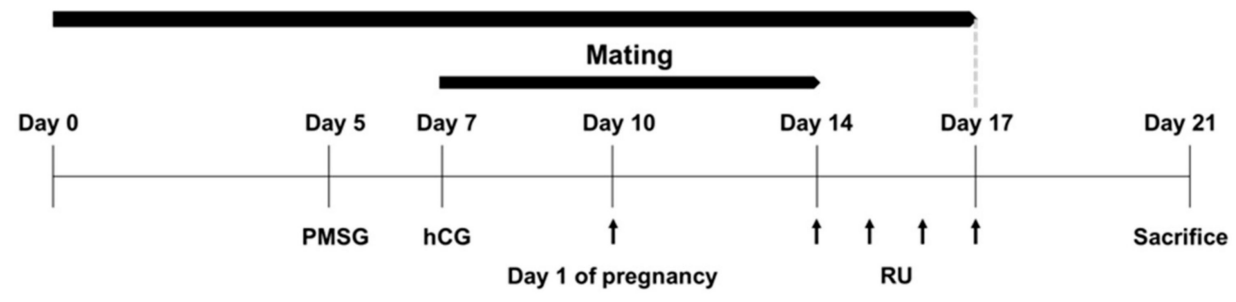

B)

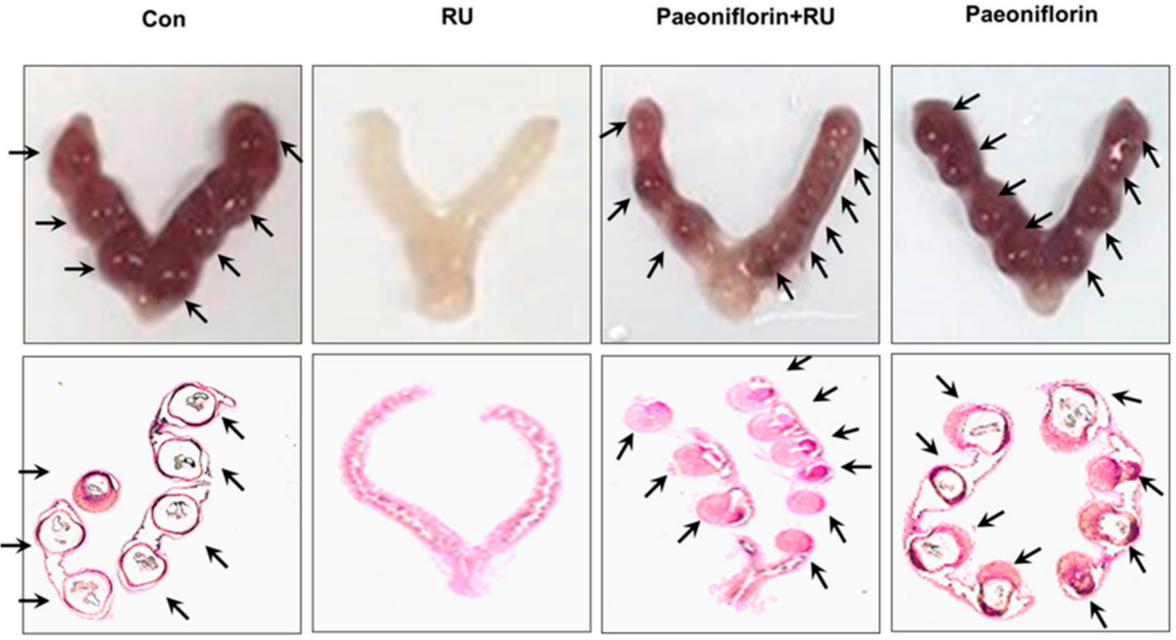

Figure 2. Cont. 


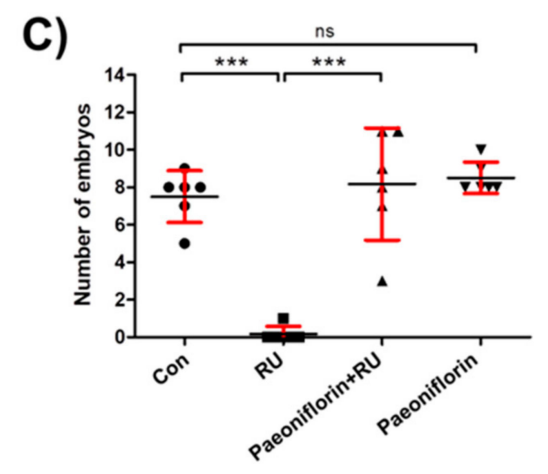

Figure 2. Paeoniflorin enhanced embryo implantation in mifepristone (RU486)-induced implantation failure mouse model. (A) Female mice were administered paeoniflorin $\left(8 \mathrm{mg} \cdot \mathrm{kg}^{-1} \cdot \mathrm{day}^{-1}\right)$ for 17 days. Seven days after paeoniflorin administration, female mice were mated with males. On day 4 from pregnancy, evidenced by vaginal plugs, female mice were daily treated with RU $\left(4 \mathrm{mg} \cdot \mathrm{kg}^{-1} \cdot \mathrm{day}^{-1}\right)$ by subcutaneous injection for 4 days. (B) Seven days after RU injections, mice were euthanized and the uteri were excised. Representative image of an embryo-implanted uterus is shown. Uterine tissue sections were stained with hematoxylin and eosin (H\&E) and histologically analyzed. (C) The number of embryo implantation sites was counted and is expressed as the mean \pm standard error of the mean (SEM); ${ }^{* * *} p<0.001$ compared to other groups; ns, no significance.

\subsection{Effect of Paeoniflorin on Adhesion between Trophoblast and Endometrial Cells}

In this study, paeoniflorin did not show significant cytotoxicity on endometrial Ishikawa cells at concentrations up to $500 \mu \mathrm{M}$ (Figure 3A). To evaluate the effect of paeoniflorin on endometrial receptivity, adhesion assays were performed with endometrial Ishikawa and fluorescently labeled trophoblastic JAr cells. Ishikawa cells treated with paeoniflorin $(50 \mu \mathrm{M})$ attached more markedly to JAr cells than the untreated control cells $(2.32 \pm 0.23$-fold, Figure 3B,C).

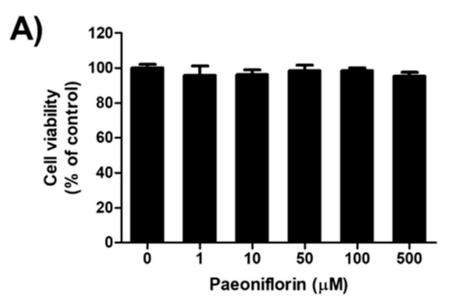

B)

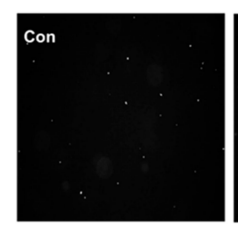

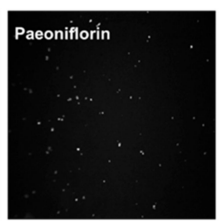

C)

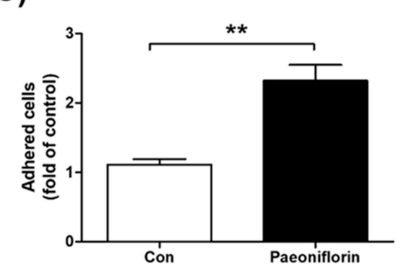

Figure 3. Cytotoxicity and effect of paeoniflorin on adhesion between endometrium and trophoblast. (A) Ishikawa cells were treated with $0,1,10,50,100$, and $500 \mu \mathrm{M}$ paeoniflorin for $24 \mathrm{~h}$. Viable cells were stained with 3-(4,5-dimethylthiazol-2-yl)-2,5-diphenyltetrazolium bromide (MTT) and the produced formazan was measured. Data were calculated as a percentage of control and are shown as the mean \pm standard error of the mean (SEM). (B) Endometrial Ishikawa cells were treated with $50 \mu \mathrm{M}$ paeoniflorin for $48 \mathrm{~h}$. Fluorescently labeled trophoblastic JAr cells were added to confluent Ishikawa cells. After incubation and washing, images of attached JAr cells were randomly captured, and representative images are shown. (C) The number of attached JAr cells was counted and calculated as a fold-change compared to control, and the results are shown as the mean \pm standard error of the mean (SEM); ${ }^{* *} p<0.01$ compared with control. 


\subsection{Role of LIF Expression on Paeoniflorin-Stimulated Cell-Cell Adhesion}

We next evaluated the effect of LIF on paeoniflorin-stimulated adhesion between endometrial cells and trophoblasts. The results demonstrated that paeoniflorin increased the expression of both messenger RNA (mRNA) and protein expression levels of LIF in a dose-dependent manner (Figure 4A). In addition, to elucidate whether LIF mediates paeoniflorin-stimulated adhesion between the endometrium and trophoblast, LIF expression was depleted using siRNA. When the expression of LIF was abolished, a significantly lower number of JAr cells attached to the paeoniflorin-treated Ishikawa cells $(1 \pm 0.12$-fold) than to the paeoniflorin-treated control cells ( $1.81 \pm 0.21$-fold, Figure 4B,C). These results suggest that LIF is a crucial mediator of paeoniflorin-stimulated endometriumtrophoblast interaction.

A)
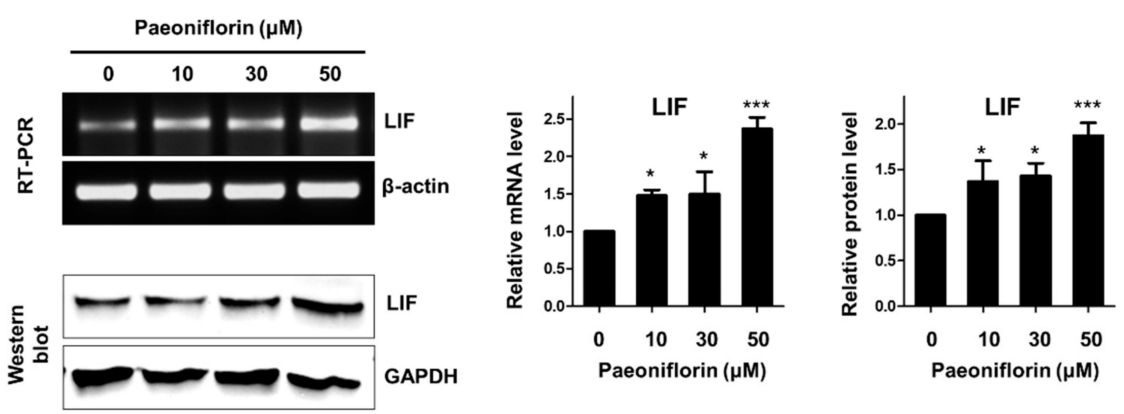

B)

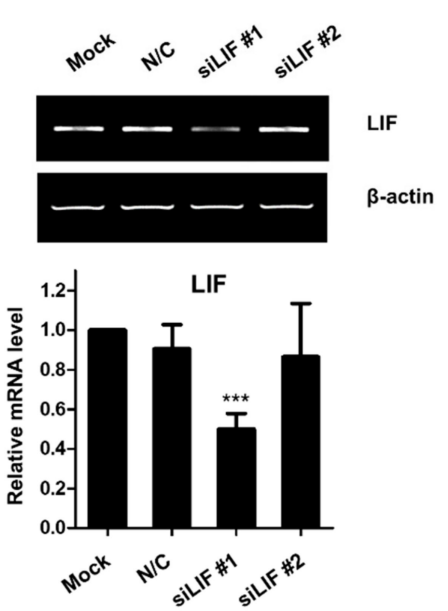

C)

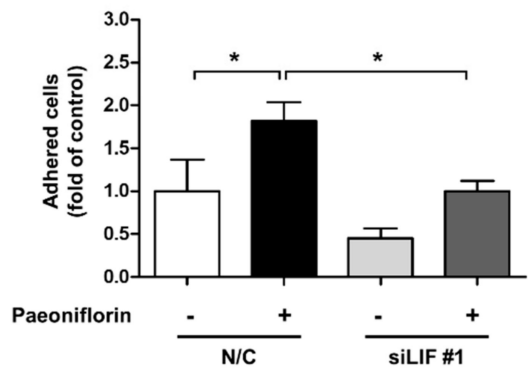

Figure 4. Paeoniflorin enhanced endometrial receptivity through expression of leukemia inhibitory factor (LIF). (A) Ishikawa cells were treated with $0,10,30$, and $50 \mu \mathrm{M}$ paeoniflorin for $24 \mathrm{~h}$. LIF expression was determined using reverse transcription polymerase chain reaction (RT-PCR) and Western blot analysis. $\beta$-Actin and glyceraldehyde 3-phosphate dehydrogenase (GAPDH) were internal controls. Relative mRNA and protein levels of LIF are shown as the mean \pm standard error of the mean (SEM); ${ }^{*} p<0.1$ and ${ }^{* * *} p<0.001$ compared to control $(0 \mu \mathrm{M})$. (B) Ishikawa cells were treated with carrier only (mock), negative control small interfering RNA (siRNA, N/C), and siRNA against LIF. After $24 \mathrm{~h}$ incubation, LIF expression was determined using RT-PCR. The relative mRNA level of LIF is shown as the mean \pm standard error of the mean (SEM); ${ }^{* * *} p<0.001$ compared to mock. (C) Ishikawa cells were transfected with N/C or siRNA against LIF. These cells were treated with or whithout $50 \mu \mathrm{M}$ paeoniflorin for $48 \mathrm{~h}$ (labelled with,+- ). Fluorescently labeled JAr cells were added to confluent Ishikawa cells. After incubation and washing, the number of attached JAr cells was counted and calculated as a fold-change compared to control, and the results are shown as the mean \pm standard error of the mean (SEM); ${ }^{*} p<0.01$ compared to each group. 


\subsection{Validation of LIF as a Target for Human Endometrial Receptivity}

To confirm that LIF is critical in human implantation, we analyzed transcriptomic data obtained from the human endometrium (GSE71835 + GSE92324, GSE26787, and GSE4888). We performed gene set enrichment analysis using the National Center for Biotechnology Information (NCBI) Gene Expression Omnibus (GEO) database. According to the Hallmark gene sets, the expression of genes involved in allograft rejection and interleukin (IL)6/Janus kinase (JAK)/signal transducer and activator of transcription 3 (STAT3) signaling was upregulated more in the normal endometrium than in the endometrium from RIF patients (GSE71835 + GSE92324, and GSE26787). Furthermore, the levels were more upregulated in the mid-secretory phase than they were in the proliferative phase (GSE4888, Figure $5 \mathrm{~A}-\mathrm{C})$.

A)

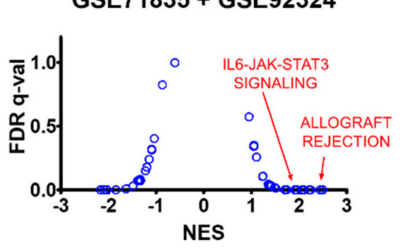

B)

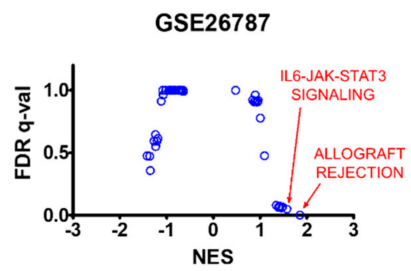

C)

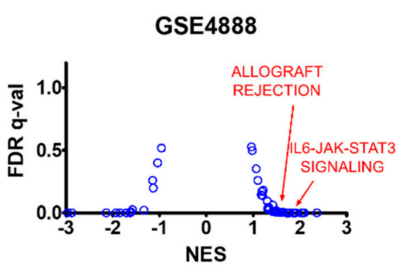

F)

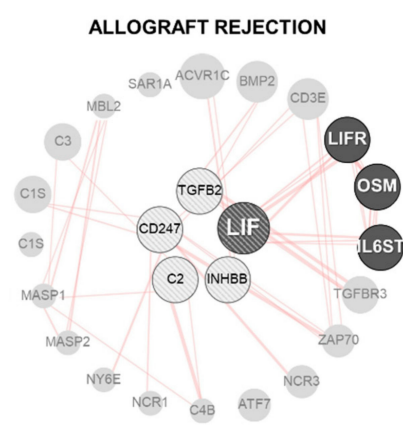

D)

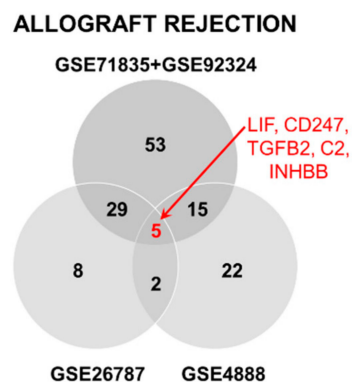

E)

IL6-JAK-STAT3 SIGNALING GSE71835+GSE92324

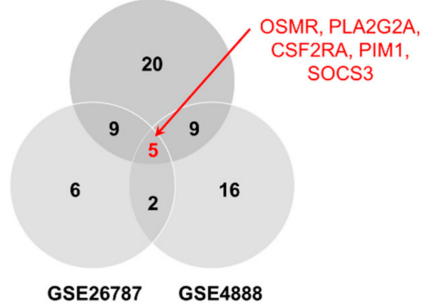

G)

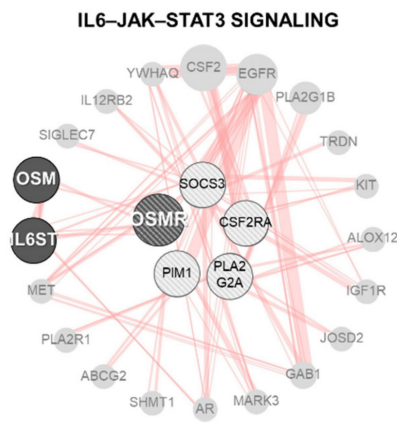

Figure 5. Gene expression profiles in human endometrium according to Hallmark gene sets. (A-C) Dot-plot graph showing ranked gene sets using normalized enrichment score (NES). Allograft rejection and interleukin-6/Janus kinase/signal transducer and activator of transcription 3 (IL-6-JAK-STAT3) signaling gene sets had NES >1.5 in normal (GSE71835 + GSE92324 and GSE26787) and secretory (GSE4888) human endometrium. (D,E) Venn diagram shows number of common genes among three transcriptomes in allograft rejection or IL-6/JAK/STAT3 signaling gene set. Five genes were in the overlapping region of each gene set. $(\mathrm{F}, \mathrm{G})$ Protein-protein interaction network of overlapping genes. Overlapping genes are located in center of a circular network. The line indicates a physical interaction between connected proteins. 
To identify the key factors among each gene set, we determined the genes that were common among the three transcriptomes. There were five genes in the overlapping region of each allograft rejection (LIF, CD247, TGFB2, C2, and INHBB) and the IL-6/JAK/STAT3 signaling (OSMR, PLA2G2A, CSF2RA, PIM1, and SOCS3) gene set (Figure 5D,E). These common genes were used to perform the protein-protein physical interaction network analysis. As shown in Figure 5F,G, allograft rejection and the IL-6/JAK/STAT3 signaling gene set were merged using IL-6 signal transducer (IL6ST) and Oncosatin M (OSM). This result suggests that the LIF and OSM pathways could be key targets in the regulation of human endometrial receptivity.

\section{Discussion}

Unexplained recurrent implantation failure is a major clinical unmet need in the treatment of female infertility, especially in the embryo transferring technique [31]. Thus, to improve the receptivity of the endometrium, many researchers have attempted to identify novel effective drugs or technologies such as intentional injury of the local endometrium [4], melatonin [32], prostaglandins [33,34], growth factors [35,36], and chemical drugs [37,38]. Several herbal drugs or their constituents have also been studied as potent candidates for the treatment of implantation failure [38-42]. Furthermore, we also reported that several herbal medicines and natural products enhance embryo implantation through an LIF-mediated mechanism [11-14].

Although the effect of $P$. lactiflora on embryo implantation was examined in our previous study [12], the precise active component mediating its endometrial receptivityenhancing effects was not elucidated. This study aimed to identify the active compound in P. lactiflora. Paeoniflorin increased LIF expression and the attachment of trophoblasts to the endometrium in the cell adhesion assay at nontoxic concentrations. Paeoniflorin improved the embryo implantation rate in the RU-induced murine implantation failure model. In addition, paeoniflorin satisfied the screening criteria for the examination of ADME processes. Although paeonol and methyl gallate induced LIF expression, they did not satisfy both the $\mathrm{OB} \geq 30 \%$ and the $\mathrm{DL} \geq 0.18$ requirements for in silico ADME analysis. Additionally, paeonol was reported to exhibit contraceptive activity in mice [43] and, therefore, we suggest that paeoniflorin is a major active compound mediating the improved endometrial receptivity.

LIF has been generally accepted to play a key role in regulating uterine receptivity. However, a controversial report suggests that LIF alone is not sufficient for assessing the implantation potential in humans [44]. LIF gene mutation does not frequently occur in infertile women [45], and recombinant human LIF did not improve implantation rates after in vitro fertilization (IVF) [46]. On the other hand, recent mRNA sequencing studies revealed that LIF/STAT3 signaling is reduced in the endometrium of RIF patients [47]. However, the female volunteers who provided endometrial tissues were all Korean.

To estimate the correlation between LIF and endometrial receptivity in humans, we analyzed several NCBI GEO data of human endometrial tissues obtained from diverse countries including India, France, and the United States of America (USA) (GSE71835 + GSE92324, GSE26787, and GSE4888). According to the GSEA, the genes involved in allograft rejection and IL-6/JAK/STAT3 signaling were related to high endometrial receptivity in the three NCBI GEO datasets. The allograft rejection pathway is the adaptive immune response for allotransplantation, which is the transplantation of a tissue or organ into an individual from a genetically different donor of the same species [48], and it is mediated by diverse cytokines [49].

Among the IL-6 family of cytokines, IL-6, LIF, and OSM are regarded as critical regulators [50]. Their receptors consist of two subunits containing at least one gp130 molecule, which is also known as IL6ST [51]. Therefore, all IL-6 family cytokines can trigger the IL-6/JAK/STAT3 signal through the gp130 subunit of their receptors [52]. This indicates that allograft rejection and IL-6/JAK/STAT3 signaling are closely related. Our GSEA results showed that these two gene sets were upregulated in the normal endometrium, 
suggesting that the LIF/IL6ST/JAK/STAT3 signaling axis might be critical for human endometrial receptivity.

Although we demonstrated that paeoniflorin enhanced endometrial receptivity in vivo and in vitro by expressing LIF, the detailed molecular mechanisms were not fully examined. First, the mechanism via which paeoniflorin induces LIF expression was not established in this study. LIF is regulated by diverse pathways, such as p53, estrogen receptor $\alpha$, JAK/STAT3, protein kinase B (AKT), extracellular signal-regulated kinase $\frac{1}{2}$ (ERK1/2), and mammalian target of rapamycin (mTOR) signaling $[7,53,54]$. To elucidate the mechanism, the precise molecular target of paeoniflorin mediating LIF induction should be identified. Several previous studies revealed the molecular targets of paeoniflorin, such as adenosine A1 receptor, liver $\mathrm{X}$ receptor, $\mathrm{N}$-methyl-D-aspartate receptor, and cannabinoid receptor 2 [55-57]. However, no previous study revealed the involvement of these molecular targets in LIF expression. Therefore, further investigations into which targets are related to LIF induction are required. Second, a previous study showed that adhesion molecules, especially integrins, such as integrin $\alpha 1, \alpha 4, \alpha \mathrm{V}, \beta 1$, and $\beta 5$, mediate the attachment between the embryo and endometrium [58]. The expression of integrins has also been reported to be diminished in the endometrium of infertile patients [59] and affected by LIF [8-10,12]. In addition, OSM, which is significantly upregulated in normal endometrial transcriptomes, has also been reported to promote embryo implantation in mice, and its expression is affected by LIF [60]. Thus, to precisely understand the mechanism via which paeoniflorin enhances endometrial receptivity, further extensive studies of these molecular targets are needed, including OSM and adhesion molecules.

To the best of our knowledge, there is no previous report on the toxicity or safety of paeoniflorin, especially its genotoxicity or reproductive toxicity. Several previous studies have shown that paeoniflorin reduced the growth of various tumor cell lines through cell-cycle arrest [61-65]. However, many studies have reported the preventive effects of paeoniflorin against renal injury [66], neurotoxicity [67], and hepatotoxicity [68]. In this study, paeoniflorin did not show cytotoxicity against human endometrial adenoma Ishikawa cells. An in vivo study also showed that paeoniflorin does not significantly affect liver and kidney functions. In addition, histological examinations showed no significant evidence of fetal regression in the paeoniflorin-treated groups. These results collectively suggest that paeoniflorin did not exhibit severe toxicity on the embryo or maternal mice at the dose used in this study.

\section{Conclusions}

In conclusion, we showed that paeoniflorin, a major component of P. lactiflora, enhanced endometrial receptivity in both in vitro and in vivo models through the expression of LIF. Although the clinical efficacy and safety of paeoniflorin should be confirmed by further extensive experiments, we suggest that paeoniflorin is a potent, potential candidate for improving the receptivity of the endometrium and, consequently, treating implantation failure.

Supplementary Materials: The following are available online at https:/ / www.mdpi.com/2218-273 X/11/3/439/s1: Figure S1. Structures of paeoniflorin derivatives in screened compound list of Paeonia lactiflora obtained from Traditional Chinese Medicine Systems Pharmacology (TCMSP) analysis; Figure S2. Effect of paeoniflorin on liver and kidney toxicity; Figure S3. Gene set enrichment analysis (GSEA) enrichment plots of allograft rejection and interleukin-6/Janus kinase/signal transducer and activator of transcription 3 (IL-6/JAK/STAT3) signaling gene sets; Table S1. Pharmacokinetic (PK) parameters of gallic acid, methyl gallate, and paeonol analyzed by Traditional Chinese Medicine Systems Pharmacology (TCMSP); Table S2. The Hallmark analysis of GSE71835 + 92324; Table S3. The Hallmark analysis of GSE26787; Table S4. The Hallmark analysis of GSE4888.

Author Contributions: Conceptualization, K.-T.H.; methodology, H.-J.C. and T.-W.C.; validation, H.-R.P., H.-J.C., B.-S.K., J.-K.J., and S.-J.B.; investigation, H.-R.P., H.-J.C., B.-S.K., and K.-J.K.; data curation, H.-R.P. and D.R.; writing-original draft preparation, H.-R.P.; writing-review and editing, K.-T.H.; supervision, K.-T.H.; funding acquisition, K.-T.H. All authors have read and agreed to the published version of the manuscript. 
Funding: This research was supported by a grant from the Korea Health Technology R\&D Project through the Korea Health Industry Development Institute (KHIDI), funded by the Ministry of Health and Welfare, Republic of Korea (Grant no. HF20C0055).

Institutional Review Board Statement: The study was conducted according to the guidelines of the Declaration of Helsinki, and approved by Animal Research Ethics Committee of Pusan University of Korea (no. PNU-2017-1606).

Informed Consent Statement: Not applicable.

Data Availability Statement: Publicly available datasets were analyzed in this study. These data can be found as https: / / www.ncbi.nlm.nih.gov / (accessed on 15 March 2021) GSE71835, GSE92324, and GSE4888.

Conflicts of Interest: There are no conflicts of interest to declare.

\section{References}

1. Von Grothusen, C.; Lalitkumar, S.; Boggavarapu, N.R.; Gemzell-Danielsson, K.; Lalitkumar, P.G. Recent Advances in Understanding Endometrial Receptivity: Molecular Basis and Clinical Applications. Am. J. Reprod. Immunol. 2014, 72, 148-157. [CrossRef]

2. Valdes, C.T.; Schutt, A.; Simon, C. Implantation failure of endometrial origin: It is not pathology, but our failure to synchronize the developing embryo with a receptive endometrium. Fertil. Steril. 2017, 108, 15-18. [CrossRef]

3. Miravet-Valenciano, J.A.; Rincon-Bertolin, A.; Vilella, F.; Simon, C. Understanding and improving endometrial receptivity. Curr. Opin. Obstet. Gynecol. 2015, 27, 187-192. [CrossRef] [PubMed]

4. Yang, J.-H.; Chen, C.-D.; Chou, C.-H.; Wen, W.-F.; Tsao, P.-N.; Lee, H.; Chen, S.-U. Intentional endometrial injury increases embryo implantation potentials through enhanced endometrial angiogenesis. Biol. Reprod. 2018, 100, 381-389. [CrossRef]

5. Cecchino, G.N.; García-Velasco, J.A. Endometrioma, fertility, and assisted reproductive treatments: Connecting the dots. Curr. Opin. Obstet. Gynecol. 2018, 30, 223-228. [CrossRef]

6. Rosario, G.X.; Stewart, C.L. The Multifaceted Actions of Leukaemia Inhibitory Factor in Mediating Uterine Receptivity and Embryo Implantation. Am. J. Reprod. Immunol. 2016, 75, 246-255. [CrossRef]

7. Hu, W.; Feng, Z.; Teresky, A.K.; Levine, A.J. p53 regulates maternal reproduction through LIF. Nature 2007, 450, 721-724. [CrossRef]

8. Chung, T.-W.; Park, M.-J.; Kim, H.S.; Choi, H.-J.; Ha, K.-T. Integrin $\alpha \mathrm{V} \beta 3$ and $\alpha \mathrm{V} \beta 5$ are required for leukemia inhibitory factor-mediated the adhesion of trophoblast cells to the endometrial cells. Biochem. Biophys. Res. Commun. 2016, 469, 936-940. [CrossRef] [PubMed]

9. Germeyer, A.; Savaris, R.F.; Jauckus, J.; Lessey, B. Endometrial beta3 Integrin profile reflects endometrial receptivity defects in women with unexplained recurrent pregnancy loss. Reprod. Biol. Endocrinol. 2014, 12, 53. [CrossRef]

10. Kang, Y.-J.; Forbes, K.; Carver, J.; Aplin, J.D. The role of the osteopontin-integrin $\alpha v \beta 3$ interaction at implantation: Functional analysis using three different in vitro models. Hum. Reprod. 2014, 29, 739-749. [CrossRef] [PubMed]

11. Choi, H.-J.; Chung, T.-W.; Park, M.-J.; Kim, H.S.; You, S.; Lee, M.S.; Joo, B.S.; Lee, K.S.; Kim, K.-J.; Wee, G.; et al. Benzoic Acid Enhances Embryo Implantation through LIF-Dependent Expression of Integrin alphaVbeta3 and alphaVbeta5. J. Microbiol. Biotechnol. 2017, 27, 668-677. [CrossRef]

12. Choi, H.-J.; Chung, T.-W.; Park, M.-J.; Lee, K.S.; Yoon, Y.; Kim, H.S.; Lee, J.H.; Kwon, S.-M.; Lee, S.-O.; Kim, K.-J.; et al. Paeonia lactiflora Enhances the Adhesion of Trophoblast to the Endometrium via Induction of Leukemia Inhibitory Factor Expression. PLOS ONE 2016, 11, e0148232. [CrossRef]

13. Choi, H.-J.; Chung, T.-W.; Park, M.-J.; Jung, Y.-S.; Lee, S.-O.; Kim, K.-J.; Ha, K.-T. Water-extracted tubers of Cyperus rotundus L. enhance endometrial receptivity through leukemia inhibitory factor-mediated expression of integrin $\alpha \mathrm{V} \beta 3$ and $\alpha \mathrm{V} \beta 5$. J. Ethnopharmacol. 2017, 208, 16-23. [CrossRef] [PubMed]

14. Kim, E.-Y.; Choi, H.-J.; Chung, T.-W.; Choi, J.-Y.; Kim, H.S.; Jung, Y.-S.; Lee, S.-O.; Ha, K.-T. Water-extracted Perilla frutescens increases endometrial receptivity though leukemia inhibitory factor-dependent expression of integrins. J. Pharmacol. Sci. 2016, 131, 259-266. [CrossRef]

15. Chevallier, A. The Encyclopedia of Medicinal Plants; Dorling Kindersley: London, UK, 1996.

16. Zhang, J.; Dou, W.; Zhang, E.; Sun, A.; Ding, L.; Wei, X.; Chou, G.; Mani, S.; Wang, Z. Paeoniflorin abrogates DSS-induced colitis via a TLR4-dependent pathway. Am. J. Physiol. Gastrointest. Liver Physiol. 2014, 306, G27-G36. [CrossRef] [PubMed]

17. Parker, S.; May, B.; Zhang, C.; Zhang, A.L.; Lu, C.; Xue, C.C. A Pharmacological Review of Bioactive Constituents of Paeonia lactiflora Pallas and Paeonia veitchii Lynch. Phytother. Res. 2016, 30, 1445-1473. [CrossRef] [PubMed]

18. Xin, Q.; Yuan, R.; Shi, W.; Zhu, Z.; Wang, Y.; Cong, W. A review for the anti-inflammatory effects of paeoniflorin in inflammatory disorders. Life Sci. 2019, 237, 116925. [CrossRef]

19. Ji, Y.; Yuan, R.; Zhao, Q.W.; Zhang, J.Z.; Yang, Y.; Wang, T.; Xia, Y.F.; Dai, Y.; Wei, Z.F. Paeoniflorin suppresses TGF- $\beta$ mediated epithelial-mesenchymal transition in pulmonary fibrosis through a Smad-dependent pathway. Acta Pharmacol. Sin. 2016, 37, 794-804. [CrossRef] [PubMed] 
20. Li, Y.-C.; Qiao, J.-Y.; Wang, B.-Y.; Bai, M.; Shen, J.-D.; Cheng, Y.-X. Paeoniflorin Ameliorates Fructose-Induced Insulin Resistance and Hepatic Steatosis by Activating LKB1/AMPK and AKT Pathways. Nutritients 2018, 10, 1024. [CrossRef] [PubMed]

21. Eun-Yeong, K.; Tae-Wook, C.; Hee-Jung, C.; Ki-Tae, H.; Yeon-Seop, J.; Syng-Ook, L.; Jun-Yong, C.; Hyung Sik, K.; Sooseong, Y.; Myeong Soo, L. Extracts from Paeonia lactiflora Pallas, Rehmannia Glutinosa var. Purpurea Makino, Perilla Frutescens var. Acuta Kudo may increase the endometrial receptivity through expression of leukemia inhibitory factor and adhesion molecules. $J$. Tradit. Chin. Med. 2019, 39, 25.

22. Kumar, P.; Nagarajan, A.; Uchil, P.D. Analysis of Cell Viability by the MTT Assay. Cold Spring Harb. Protoc. 2018. [CrossRef]

23. Gershoni, J.M.; Palade, G.E. Protein blotting: Principles and applications. Anal. Biochem. 1983, 131, 1-15. [CrossRef]

24. Salvatore, B. Assaying cell-cell adhesion. Methods Mol. Biol. 2006, 46, 449-467.

25. Pathare, A.D.S.; Zaveri, K.; Hinduja, I. Downregulation of genes related to immune and inflammatory response in IVF implantation failure cases under controlled ovarian stimulation. Am. J. Reprod. Immunol. 2017, 78. [CrossRef] [PubMed]

26. Lédée, N.; Munaut, C.; Aubert, J.; Sérazin, V.; Rahmati, M.; Chaouat, G.; Sandra, O.; Foidart, J.M. Specific and extensive endometrial deregulation is present before conception in IVF/ICSI repeated implantation failures (IF) or recurrent miscarriages. J. Pathol. 2011, 225, 554-564. [CrossRef]

27. Talbi, S.; Hamilton, A.E.; Vo, K.C.; Tulac, S.; Overgaard, M.T.; Dosiou, C.; Le Shay, N.; Nezhat, C.N.; Kempson, R.; Lessey, B.A.; et al. Molecular phenotyping of human endometrium distinguishes menstrual cycle phases and underlying biological processes in normo-ovulatory women. Endocrinology 2006, 147. [CrossRef] [PubMed]

28. Tilford, C.A.; Siemers, N.O. Gene Set Enrichment Analysis. Methods Mol. Biol. 2009, 563, 99-121. [CrossRef]

29. Franz, M.; Rodriguez, H.; Lopes, C.; Zuberi, K.; Montojo, J.; Bader, G.D.; Morris, Q. GeneMANIA update 2018. Nucleic Acids Res. 2018, 46, W60-W64. [CrossRef] [PubMed]

30. Roblero, L.; Fernandez, O.; Croxatto, H. The effect of RU486 on transport, development and implantation of mouse embryos. Contraception 1987, 36, 549-555. [CrossRef]

31. Coughlan, C.; Ledger, W.; Wang, Q.; Liu, F.; Demirol, A.; Gurgan, T.; Cutting, R.; Ong, K.; Sallam, H.; Li, T. Recurrent implantation failure: Definition and management. Reprod. Biomed. Online 2014, 28, 14-38. [CrossRef]

32. Wang, F.; Tian, X.; Zhang, L.; Tan, D.; Reiter, R.J.; Liu, G. Melatonin promotes the in vitro development of pronuclear embryos and increases the efficiency of blastocyst implantation in murine. J. Pineal Res. 2013, 55, 267-274. [CrossRef] [PubMed]

33. Huang, X.; Liu, H.; Li, R. Prostaglandin E2 promotes BeWo spheroids implantation in RL95-2 cell monolayers. Gynecol. Endocrinol. 2017, 33, 548-552. [CrossRef] [PubMed]

34. Kaczynski, P.; Kowalewski, M.P.; Waclawik, A. Prostaglandin F2 $\alpha$ promotes angiogenesis and embryo-maternal interactions during implantation. Reproduction 2016, 151, 539-552. [CrossRef]

35. Naghshineh, E.; Eftekhar, M.; Khani, P. Role of granulocyte colony-stimulating factor in human reproduction. J. Res. Med. Sci. 2018, 23, 7. [CrossRef] [PubMed]

36. Paule, S.; Nebl, T.; Webb, A.I.; Vollenhoven, B.; Rombauts, L.J.F.; Nie, G. Proprotein convertase 5/6 cleaves platelet-derived growth factor A in the human endometrium in preparation for embryo implantation. Mol. Hum. Reprod. 2015, 21, 262-270. [CrossRef] [PubMed]

37. Li, J.; Chen, Y.; Wang, A.; Zhang, H. A meta-analysis of atosiban supplementation among patients undergoing assisted reproduction. Arch. Gynecol. Obstet. 2017, 296, 623-634. [CrossRef]

38. Zhang, Y.-M.; Zhang, Y.-Y.; Bulbul, A.; Shan, X.; Wang, X.-Q.; Yan, Q. Baicalin promotes embryo adhesion and implantation by upregulating fucosyltransferase IV (FUT4) via Wnt/beta-catenin signaling pathway. FEBS Lett. 2015, 589, 1225-1233. [CrossRef]

39. Fang, L.; Rui-Xia, W.; Feng-Mei, M.; Zhen-Gao, S.; Li-Hong, W.; Lei, S. Effects of Chinese Medicines for Tonifying the Kidney on DNMT1 Protein Expression in Endometrium of Infertile Women During Implantation Period. J. Altern. Complement. Med. 2013, 19, 353-359. [CrossRef] [PubMed]

40. Yu, N.; Yang, J.; Yin, T. Extracts from a traditional Chinese herbal remedy (Zhuyun recipe) improve endometrial receptivity in mice with embryonic implantation dysfunction and ovulation stimulation. J. Ethnopharmacol. 2011, 137, 389-395. [CrossRef]

41. Xu, X.; Yin, H.; Tang, D.; Zhang, L.; Gosden, R.G. Application of traditional Chinese medicine in the treatment of infertility. Hum. Fertil. 2003, 6, 161-168. [CrossRef]

42. Huang, S.-T.; Chen, A.P.-C. Traditional Chinese medicine and infertility. Curr. Opin. Obstet. Gynecol. 2008, 20, 211-215. [CrossRef]

43. Wu, B.; Zhao, T.D.; Guan, S.H. Study on the effect of Paeonol on the contraception of mouse. J. Physiol. Pathol. Korean Med. 1980, $4,43-44$.

44. Aghajanova, L. Update on the role of leukemia inhibitory factor in assisted reproduction. Curr. Opin. Obstet. Gynecol. 2010, 3, 213-219. [CrossRef]

45. Steck, T.; Giess, R.; Suetterlin, M.W.; Bolland, M.; Wiest, S.; Poehls, U.G.; Dietl, J. Leukaemia inhibitory factor (LIF) gene mutations in women with unexplained infertility and recurrent failure of implantation after IVF and embryo transfer. Eur. J. Obstet. Gynecol. Reprod. Biol. 2004, 112, 69-73. [CrossRef]

46. Brinsden, P.R.; Alam, V.; de Moustier, B.; Engrand, P. Recombinant human leukemia inhibitory factor does not improve implantation and pregnancy outcomes after assisted reproductive techniques in women with recurrent unexplained implantation failure. Fertil. Steril. 2009, 91, 1445-1447. [CrossRef] [PubMed] 
47. Choi, Y.; Hye-Ryun, K.; Lim, E.J.; Park, M.; Yoon, J.A.; Kim, Y.S.; Kim, E.K.; Shin, J.E.; Kim, J.H.; Kwon, H.; et al. Integrative Analyses of Uterine Transcriptome and MicroRNAome Reveal Compromised LIF-STAT3 Signaling and Progesterone Response in the Endometrium of Patients with Recurrent/Repeated Implantation Failure (RIF). PLoS ONE 2016, 11, e0157696. [CrossRef] [PubMed]

48. Lin, C.M.; Gill, R.G. Direct and indirect allograft recognition: Pathways dictating graft rejection mechanisms. Curr. Opin. Organ Transplant. 2016, 21, 40-44. [CrossRef] [PubMed]

49. Gorczynski, R.M. Role of cytokines in allograft rejection. Curr. Pharm. Des. 2001, 7, 1039-1057. [CrossRef]

50. Jordan, S.C.; Choi, J.; Kim, I.; Wu, G.; Toyoda, M.; Shin, B.; Vo, A. Interleukin-6, A Cytokine Critical to Mediation of Inflammation, Autoimmunity and Allograft Rejection: Therapeutic Implications of IL-6 Receptor Blockade. Transplantation 2017, 101, 32-44. [CrossRef] [PubMed]

51. Rose-John, S. Interleukin-6 Family Cytokines. Cold Spring Harb. Perspect. Biol. 2018, 10, a028415. [CrossRef]

52. Heinrich, P.C.; Behrmann, I.; Müller-Newen, G.; Schaper, F.; Graeve, L. Interleukin-6-type cytokine signalling through the gp130/Jak/STAT pathway. Biochem. J. 1998, 334, 297-314. [CrossRef]

53. Yue, X.; Wu, L.; Hu, W. The regulation of leukemia inhibitory factor. Cancer Cell Microenviron. 2015,2 , e877.

54. Chen, J.R.; Cheng, J.-G.; Shatzer, T.; Sewell, L.; Hernandez, L.; Stewart, C.L. Leukemia Inhibitory Factor Can Substitute for Nidatory Estrogen and Is Essential to Inducing a Receptive Uterus for Implantation But Is Not Essential for Subsequent. Endocrinology 2000, 141, 4365-4372. [CrossRef]

55. Lin, H.R. Paeoniflorin acts as a liver X receptor agonist. J. Asian Nat. Prod. Res. 2013, 15, 35-45. [CrossRef] [PubMed]

56. Liu, D.Z.; Xie, K.-Q.; Ji, X.-Q.; Ye, Y.; Jiang, C.-L.; Zhu, X.-Z. Neuroprotective effect of paeoniflorin on cerebral ischemic rat by activating adenosine A1 receptor in a manner different from its classical agonists. Br. J. Pharmacol. 2005, 146, 604-611. [CrossRef] [PubMed]

57. Chen, A.; Wang, H.; Zhang, Y.; Wang, X.; Yu, L.; Xu, W.; Xu, W.; Lin, Y. Paeoniflorin exerts neuroprotective effects against glutamate induced PC12 cellular cytotoxicity by inhibiting apoptosis. Int. J. Mol. Med. 2017, 40, 825-833. [CrossRef]

58. Wang, J.; Armant, D.R. Integrin-mediated adhesion and signaling during blastocyst implantation. Cells Tissues Organs 2002, 172, 190-201. [CrossRef] [PubMed]

59. Lessey, B.A.; Castelbaum, A.; Sawin, S.W.; Sun, J. Integrins as markers of uterine receptivity in women with primary unexplained infertility. Fertil. Steril. 1995, 63, 535-542. [CrossRef]

60. Fu, T.; Zheng, H.-T.; Zhang, H.-Y.; Chen, Z.-C.; Li, B.; Yang, Z.-M. Oncostatin M expression in the mouse uterus during early pregnancy promotes embryo implantation and decidualization. FEBS Lett. 2019, 593, 2040-2050. [CrossRef] [PubMed]

61. Zhang, J.-W.; Li, L.-X.; Wu, W.-Z.; Pan, T.-J.; Yang, Z.-S.; Yang, Y.-K. Anti-Tumor Effects of Paeoniflorin on Epithelial-ToMesenchymal Transition in Human Colorectal Cancer Cells. Med. Sci. Monit. 2018, 24, 6405-6413. [CrossRef] [PubMed]

62. Ouyang, J.; Xu, H.; Li, M.; Dai, X.; Fu, F.; Zhang, X.; Lan, Q. Paeoniflorin exerts antitumor effects by inactivating S phase kinase-associated protein 2 in glioma cells. Oncol. Rep. 2018, 39, 1052-1062. [CrossRef]

63. Yue, M.; Li, S.; Yan, G.; Li, C.; Kang, Z. Paeoniflorin inhibits cell growth and induces cell cycle arrest through inhibition of FoxM1 in colorectal cancer cells. Cell Cycle 2018, 17, 240-249. [CrossRef]

64. Zhang, J.; Yu, K.; Han, X.; Zhen, L.; Liu, M.; Zhang, X.; Ren, Y.; Shi, J. Paeoniflorin influences breast cancer cell proliferation and invasion via inhibition of the Notch-1 signaling pathway. Mol. Med. Rep. 2018, 17, 1321-1325. [CrossRef] [PubMed]

65. Zhang, J.; Wang, F.; Wang, H.; Wang, Y.; Wu, Y.; Xu, H.; Su, C. Paeoniflorin inhibits proliferation of endometrial cancer cells via activating MAPK and NF-kB signaling pathways. Exp. Ther. Med. 2017, 14, 5445-5451. [CrossRef]

66. Lu, R.; Zhou, J.; Liu, B.; Liang, N.; He, Y.; Bai, L.; Zhang, P.; Zhong, Y.; Zhou, Y.; Zhou, J. Paeoniflorin ameliorates Adriamycininduced nephrotic syndrome through the PPAR $\gamma /$ ANGPTL4 pathway in vivo and vitro. Biomed. Pharmacother. 2017, 96, 137-147. [CrossRef] [PubMed]

67. Zheng, M.; Liu, C.; Fan, Y.; Yan, P.; Shi, D.; Zhang, Y. Neuroprotection by Paeoniflorin in the MPTP mouse model of Parkinson's disease. Neuropharmacology 2017, 116, 412-420. [CrossRef] [PubMed]

68. Kim, I.D.; Ha, B.J. The effects of paeoniflorin on LPS-induced liver inflammatory reactions. Arch. Pharmacal Res. 2010, 33, 959-966. [CrossRef] 